\title{
Bridging theory and practice in ecosystem services mapping: a systematic review
}

\author{
Rachel E. Bitoun $^{1}\left[\right.$ [ Ewan Trégarot ${ }^{2}\left(\mathbb{D} \cdot\right.$ Rodolphe Devillers $^{1}(\mathbb{C}$
}

Accepted: 29 November 2021 / Published online: 11 December 2021

(c) The Author(s) 2021

\begin{abstract}
The mapping and assessment of Ecosystem Services (ES) aims at better connecting environmental conservation, economic development, and human well-being. However, 60 years after the development of the ES concept, a persistent gap remains between the production of scientific knowledge on ES and its use in support of policy and management. Here, we report on a systematic review of the scientific literature that helps better understand key challenges and offers potential solutions to bridge this gap. The review considered four criteria: (1) how stakeholders participate to studies; (2) how usable ES maps are for decision-making; (3) what policy recommendations were made; and (4) what research recommendations were made. The analysis of 135 papers published between 2008 and 2020 revealed diverse technical and conceptual challenges that could prevent the effective use of ES concepts and methods outside the academic realm. The main challenges identified in the literature were the uncertainty levels of ES mapping outputs, issues of spatial scales, the understanding of ES interactions, and the need for temporal analysis. Many policies rely on mapped outcomes, creating a window of opportunity for the uptake of ES mapping into policy-making. However, it remains key to involve stakeholders early in the co-design of ES studies and to better understand their preferences and motivation to adopt ES mapping in their practices. The study shows that higher levels of learnability of ES mapping practices, further popularization to foster public awareness, and increased capacity building would facilitate the ES concept uptake into decision and policy-making.
\end{abstract}

Keywords Decision-making $\cdot$ Usability $\cdot$ Stakeholder participation $\cdot$ Science-practice gap $\cdot$ Ergonomics principles

\section{Introduction}

For over a decade, the concept of Ecosystem Services (ES) has been increasingly adopted in policy agendas to encourage the conservation of nature for the services it provides to people (Jacobs et al. 2016). Ecosystems provide diverse services to humans, such as natural disaster mitigation, carbon storage, water quality improvement, food provision, and areas for tourism (Ranganathan et al. 2008). If ES maps are now commonly used by scientists to support the

Ewan Trégarot

ewan.tregarot@port.ac.uk

1 Espace-Dev (IRD, Univ. Montpellier, Univ. Guyane, Univ. La Réunion, Univ. Antilles, Univ. Nouvelle Calédonie), Montpellier, France

2 Centre for Blue Governance, Department of Economics and Finance, Portsmouth Business School, University of Portsmouth, Richmond Building, Portland Street, Portsmouth, UK identification of priority areas for environmental conservation (Dvarskas 2018; Lorilla et al. 2020), they also recently helped raise awareness on links that exist between ecosystem conditions and human well-being (Brunet et al. 2018; Hauck et al. 2013). Such a popularity amongst researchers (Egoh et al. 2008) has been partly explained by the role ES can play in bridging the gap that often divides natural sciences and social sciences (Drius et al. 2019), helping link ecosystems' states to human well-being (Daily and Matson 2008). While ES are increasingly promoted in the scientific communities, their adoption by practitioners proved to be more difficult (Nahuelhual et al. 2016). Reasons for this are multiple and are symptomatic of a more general mismatch between science and practice due to an ongoing discussion on how the concepts could be improved, mainstreamed, and operationalized (Lautenbach et al. 2019). Studies also found practitioners have a limited understanding of ES concepts, sometimes deemed too theoretical, and do not always have the expertise, nor the time, to integrate ES approaches into their practices (Drakou et al. 2015; Johnson et al. 2019; Polasky 
et al. 2015). Indeed, if the usefulness and importance of ES mapping for decision-making have been widely discussed in the academic literature (e.g., Burkhard and Maes 2017; Egoh et al. 2008), evidence of its practical implementation in support of policy and decision-making remains scarce (Longato et al. 2021). This raises questions about the nature of the gap that separates science from practice and ways it be reduced (Chen et al. 2019; Daily and Matson 2008).

Such a gap is not unique to ES, as conservation scientists in general are increasingly expected to produce knowledge that can inform land-use management and policy-making (Brunet et al. 2018; Toomey 2016). Scientific knowledge that can be connected to society (Kerr 2011), linking knowledge with action (Carmen et al. 2018), has been referred to as 'Actionable knowledge' (Brunet et al. 2018). Knowledge is more likely to be actionable when there is a wellestablished relationship between producers and users of information (Kirchhoff et al. 2013), also referred to as 'science-practice interaction' (Jax et al. 2018). However, studies keep highlighting a persistent gap between the production of scientific knowledge and its use (e.g., Daily and Matson 2008; Jax et al. 2018; Lautenbach et al. 2019; Longato et al. 2021). Actionable knowledge can benefit from the early involvement of end-users (i.e., practitioners, policymakers, decision-makers) in the knowledge construction that can help produce information more suitable to their needs (Brunet et al. 2018). Cowling et al. (2008) called for useful ES maps, with user-friendly methods and tools used for their mapping. This favors their mainstreaming for the implementation of policies and management measures. Daily and Matson (2008) argue that a "radical transformation will be required to move from conceptual frameworks and theory to practical integration of ES into decision-making, in a way that is credible, replicable, scalable, and sustainable" (p.2).

The usability of ES maps has been discussed in reviews of case studies. For instance, Jax et al. (2018) provided ten general guiding principles for operationalizing ES assessment, although none is explicitly applicable to ES mapping. Other authors reviewed the usability of ES maps in regard to technical requirements (Zulian et al. 2018) or for their use into decision-making (Martinez-Harms et al. 2015). The review performed by Longato et al. (2021) studied the level of integration of ES knowledge into decision-making through scientific narratives expressed, limited to seven case studies. While Jax et al. (2018), Longato et al. (2021), and Zulian et al. (2018) presented case studies on the operational usability of ES concepts and maps, we carry out in this paper a state of the art of the scientific critical perspective on ES map usability through the analysis of a large body of peer-reviewed papers. Our findings could help narrow the science-practice gap in the ES mapping field, and open the debate on how to move forward. To do so, we conducted a systematic review of ES mapping studies and provided recommendations that could inform future research aiming at improving the practical use of ES mapping outcomes for decision-making.

\section{Methods}

A systematic literature review was conducted following the five-stage approach proposed by Wolfswinkel et al. (2013): (1) criteria definition, (2) literature search, (3) selection and refinement, (4) analysis, and (5) presentation.

\subsection{Criteria definition and literature search}

To perform this systematic literature search, we defined three preliminary inclusion criteria: the date of publication, the type of paper and the language of the paper published (Table 1).

We searched the Web of Science publication database on January 26th, 2021 for papers relating to the mapping of ES using selected keywords used in the papers' titles or keywords. The search (see Supplementary Materials A for the detailed query) used the terms "ecological service", "ecosystem service", "environmental service", associated with "mapping", and variations on those terms (e.g., plural form) that could limit semantic biases, as recommended by de Araujo Barbosa et al. (2015).

\subsection{Selection and refinement}

The selection and refinement of papers followed PRISMA method (Preferred Reporting Items for Systematic Review; Moher et al. 2009). The preliminary search (Identification phase) identified 516 papers (Fig. 1). A screening of the titles and keywords of those papers (Screening phase) led to the exclusion of 217 papers for which ES mapping was not the main focus. Papers were then read in full to confirm

Table 1 Inclusion criteria for literature search

\begin{tabular}{|c|c|}
\hline Inclusion & Description \\
\hline Date & $\begin{array}{l}\text { Papers published between } 2008 \text { and the date } \\
\text { of the literature search. The year } 2008 \text { was } \\
\text { selected to examine the literature published } \\
\text { since the Daily and Matson (2008) study that } \\
\text { called for a radical transformation of the ES } \\
\text { field to move from theory to practice }\end{array}$ \\
\hline Type & $\begin{array}{l}\text { Peer-reviewed journal papers (Mengist et al. } \\
\text { 2020). While grey literature could have } \\
\text { provided insightful information, its use is not } \\
\text { possible in a systematic approach due to the } \\
\text { varied availability of those reports (approach } \\
\text { consistent with Longato et al. 2021) }\end{array}$ \\
\hline Language & Papers written in the English language \\
\hline
\end{tabular}




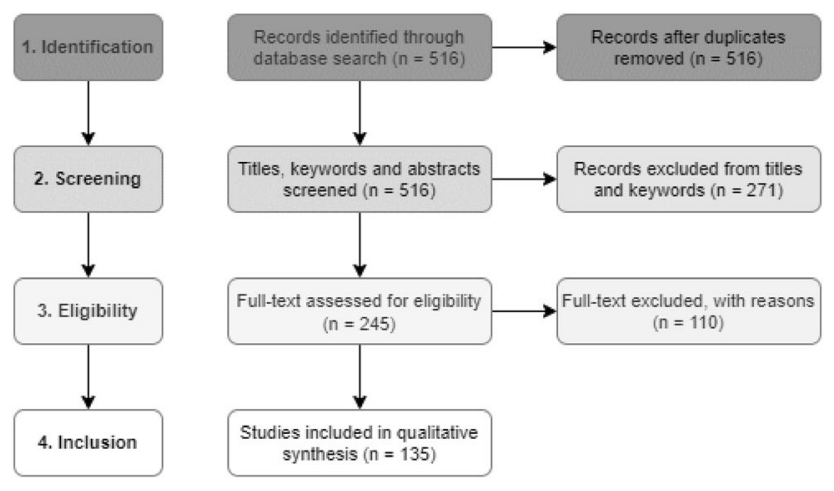

Fig. 1 Flow chart of the method and selection processes used in the systematic review, following the PRISMA method

their selection (Eligibility phase). Four additional filters were applied to refine the full-text selection.

Papers were excluded if their content did not address at least one of the following topics:

- Stakeholder participation, perceptions, and capacity building Stakeholders comprise a wide group of actors such as members of academia, government, non-governmental organizations, decision-makers, and local communities. Effective implementation of ES mapping is facilitated when it includes stakeholders' preferences in the assessment process (Beaumont et al. 2017; Burkhard and Maes 2017). We refer to stakeholder participation as a broad spectrum of ways in which those who design ES studies include other participants or assess their preferences. A mismatch is highlighted between the scientific studies and their relevance for stakeholders, especially their relevance for decision-makers (e.g., Dicks et al. 2014). Therefore, our aim is to analyze the participation levels of stakeholders in ES mapping studies and the usefulness of their involvement.

- ES map usability ES maps, as a tool, can be analyzed with ergonomic principles to assess the usability of ES maps for users. Ergonomics is a science related to designing a work environment that can favor human well-being and overall performance. Ergonomics aims at finding the best practice in terms of performance while limiting workloads, errors, and complex data processing (Joly et al. 2021). Therefore, an ergonomic design becomes more usable (i.e., capacity to be put into practice). Dix et al. (2003) developed usability principles that guided our analysis of the usability of ES maps for end-users. The usability of ES mapping methods and mapped outcomes is understood in terms of learnability (the ease to learn methods), flexibility (the possibility to adapt methods to the purpose of the study), and robustness (the scientific soundness of results). Papers discussing this criterion analyzed the usability of ES maps to support decision-making.

- Policy recommendations Policy recommendations aim to convince policy-makers of the need to change course on a specific issue. This can be done by bringing issues to their attention, framing the problem and providing potential solutions. Scientific advice is often a valuable input to sound policy-making (Dicks et al. 2014; Steel et al. 2004), especially when addressing complex challenges such as biodiversity loss and climate change (OCDE 2015). The recommended policy changes from the selected papers were collected, organized into themes, and completed with the authors' expertise. Policy recommendations made in the selected papers were only considered when they were detailed enough to demonstrate changes of course for policy-makers. Short general statements (e.g., in a single sentence) were therefore not considered.

- Research recommendations Scientific studies can result in recommendations, such as offering alternatives, suggesting ways to improve decision-making, or ways a consensus can be reached. They can also help modify a behavior towards a desired direction, increase the visibility of a new concept, and increase users' acceptance (Jannach and Adomavicius 2016). Recommendations can also help address limitations of research outcomes and suggest ways of overcoming them in the future. Therefore, recommendations stem directly from the papers' key findings. This criterion aims to provide an overview of the current challenges and limitations of studies and draw a synthesis of the proposed courses of action to pursue ES mapping uptake. Research recommendations made in the selected papers were only considered when they were detailed enough to describe practical ways to advance the application of ES studies for decision-making. Short general statements were, therefore, not considered.

This phase led to excluding an additional 119 papers. Most of them $(n=69)$ were excluded for not addressing any of our research questions. Other reasons for excluding papers were that the full-text analysis of the paper indicated that ES mapping was still not the main research topic $(n=30)$, access to the paper was impossible $(n=6)$, the paper was a review $(n=3)$, and the paper was a discussion paper $(n=1)$. The final selection comprised 135 papers that were used for full-text analysis. A complete list of the selected papers is provided in Supplementary Materials B.

\subsection{Literature analysis}

The content of each paper was analyzed using a summary coding sheet capturing information related to elements presented in Table 2. For the analysis, we adopted a combination of deductive (pre-defined selective coding) and inductive coding, 
Table 2 Coding sheet used for analysis

\begin{tabular}{ll}
\hline Category & Description \\
\hline Research area & Categorization shared by all Web of Science databases. Research areas are classified into five broad categories: \\
& (1) Arts and Humanities; (2) Life Sciences and Biomedicine; (3) Physical Sciences; (4) Social Sciences; (5) \\
& Technology \\
Themes emerged from the content analysis. In addition, following a simplified version of Arnstein's (1969) \\
ladder of participation, papers dealing with stakeholder participation were classified into sub-groups: (0) no \\
participation; (1) inform; (2) consult; (3) involve; (4) collaborate; and (5) empower. Information being the \\
least engaging type of participation, whereas empowerment is the most engaging form of participation \\
Dix et al. (2003) framework guided the analysis of the usability. Relevant excerpts from papers were classi- \\
fied into the three components of usability: (1) learnability; (2) flexibility; and (3) robustness. In addition, \\
for the analysis of flexibility, the decision contexts of the ES studies were recorded following Santos-Martin \\
et al. (2018) classification in the context of European Mapping and Assessment of ES (MAES) methodology. \\
These contexts were grouped into two categories-policy and business -, and into 14 classes: (1) awareness; \\
(2) priority setting; (3) policy and (4) project evaluation; (5) accounting; (6) instrument design; (7) litigation; \\
(8) preference assessment; (9) site and (10) operational management; (11) legal and regulatory issues; (12) \\
financing; (13) reputational and marketing; and (14) societal. Papers can have no mention of the practical \\
purposes of the ES study for decision-making or can have more than one purpose. In this case, all decision \\
contexts were taken into account for the assessment. If no statement was made on the use of the study in other \\
contexts, we recorded the study as having an academic purpose. Other uses for ES maps are possible, but for \\
the mainstreaming of ES approaches, we refer to well-accepted standards such as MAES \\
Themes emerged from the content analysis \\
Themes emerged from the content analysis
\end{tabular}

with excerpts drawn from data and grouped into themes (i.e., open coding). Themes and sections were based on the data gathered instead of starting with existing preconceptions (with the exception of participation levels and decision contexts where categories were predefined). The paper content was broken down into discrete parts. It was first divided into the four study criteria (stakeholders, usability, policy, research), and we looked in a second time for trends and patterns, themes, debates and conflicts within these four sections.

\subsection{Result presentation}

Results are presented following each of the four structuring questions on (1) stakeholder participation; (2) map usability; (3) policy; and (4) research recommendation.

A multidimensional scaling scatterplot was performed using JMP16 software to display the relative position of participation levels and decision context variables in order to analyze the similarity and dissimilarity (in terms of distance) of each variable to one another. Data were scaled from one to nine to limit potential biases due to paper selection. Calculations performed to construct the multidimensional scaling scatterplot are available in Supplementary Materials D.

\section{Results}

Most papers analyzed (86\%) fall under the broad research area of 'Life Sciences' defined in the Web of Science Collection. As part of this group, papers mainly belong to the fields of 'Environmental Sciences' (34.1\%), 'Ecology' (34.1\%), and 'Biodiversity and Conservation' (13.9\%). Papers in 'Social Sciences' represent about $6 \%$ of the literature analyzed, dominated by 'Business and Economics' (2.6\%). Papers related to 'Technologies' (2\%), 'Physical Geography' (1.2\%), 'Oceanography' (0.9\%), and 'Water resources' $(0.9 \%)$ dominate the remaining $8 \%$. About $2.3 \%$ of the papers were classified under 'Other topic'.

The usability of maps for decision-making is the most studied of the four criteria $(71.9 \%, n=97$, Fig. 2), followed by the recommendations for future research for improving ES map operational usability $(66.7 \%, n=90)$, the recommendations for effective policy implementation $(48.9 \%, n=66)$, and by the integration of stakeholder in the research design

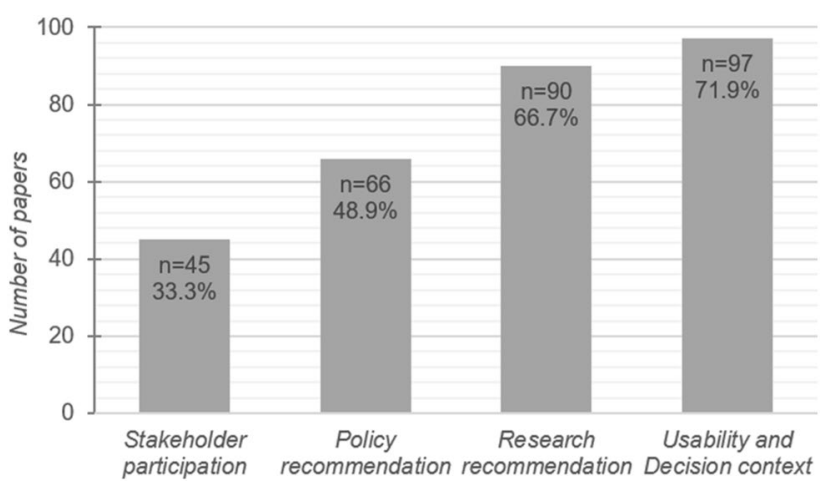

Fig. 2 Occurrence and percentage of the studied criteria in the papers collected $(n=135)$ 
$(33.3 \%, n=45)$. Only $12.6 \%$ of the papers discuss all four criteria, 37\% covered two of the four criteria, and about a quarter of papers (respectively $24.4 \%$ and $25.9 \%$ ) cover one or three critera (Table 1, Supplementary Material C).

Figure 3 represents the distances between stakeholder participation levels and decision contexts. Proximity between variables indicate stronger relationships between those variables in the literature analyzed. Three main clusters (A, B, and C) emerge on the map. Cluster A, with the highest density, has 'academic' as central variable. Academic has a strong relationship with eight decision contexts (e.g., 'project evaluation' and 'priority setting') and one participation level ('no participation'). Clusters B and C have lower densities. B is clustered around 'consult' to which are linked two other participation levels ('inform' and 'collaborate') and the decision context 'preference assessment'. C clusters 'involve' and 'societal'. Other variables are scattered independently on the plot with strong dissimilarity to other variables. For example, 'legal and regulatory issues', 'awareness', and 'reputational and marketing' present the strongest dissimilarities to other variables. Clusters A and B are highly dissimilar, while $\mathrm{B}$ and $\mathrm{C}$ remain close.

\subsection{How were stakeholders participating?}

We found $65.2 \%(n=88)$ of studies did not report any stakeholder participation (Table 2, Supplementary Materials C). If $34.8 \%$ had stakeholders participating, only $2.2 \%(n=3)$ did so through empowerment, while $16.3 \%$ had stakeholders 'involved' and $7.4 \%$ were 'consulted'. Involvement was mostly used in expert-scoring and stakeholder workshops, taking advantage of stakeholder knowledge to increase the accuracy of ES maps. Consultations occurred mostly when stakeholders answered surveys on their preferences (Cluster B, Fig. 3). Indeed, the distance map demonstrated a link between 'preference assessment', 'consult', 'inform', and 'collaborate'. The highest levels of participation (empower and collaborate) show important distances to most decision contexts clustered in group A.

The second most recurring type of participation level was collaboration $(8.9 \%)$, which mainly took the form of participatory mapping approaches to evaluate policy impacts. None of the studies used 'Inform' as a type of stakeholder participation. This could find an explanation in the poor use of ES mapping studies for 'Awareness' raising (1.5\%).

From the content analysis of the selected papers, we found several authors faced obstacles in co-developing studies with stakeholders due to a lack of understanding of the concepts. This was especially true in countries where ES concepts have been adopted recently. However, we found many studies arguing for the benefits of considering stakeholder preferences and knowledge (34.8\%). This includes considering information on the context of the study area in terms of connections humans maintain with their environment and better understanding what benefits populations. It also includes identifying stakeholder networks, their perceptions, interactions between stakeholder groups, as well as identifying conflicts over natural resource exploitation and land use, and developing acceptable policies.

\subsection{How usable are ES maps for decision-making?}

Another general topic that emerged from the literature was the question of usability of ES maps. As defined by Dix et al. (2003), a concept/tool (ES mapping methods and outcomes in our context) can be considered as being usable according to ergonomics principles when it is flexible, learnable, and robust. We used this framework to assess the overall usability of ES maps.

Many papers discussed the flexibility in the application of their ES mapping methodology for decision-making. Indeed, the broad range of decision contexts ES maps are used for are a testimony to the flexibility of ES mapping. Most papers addressing the usability of ES concepts and

Fig. 3 Multidimensional scaling plot applied to 'stakeholder participation' (italics) and 'decision contexts' (normal) in ecosystem services mapping studies. Variables closer on the plot are more often related in the literature. Data density ranges from blue (low density) to red (high density)

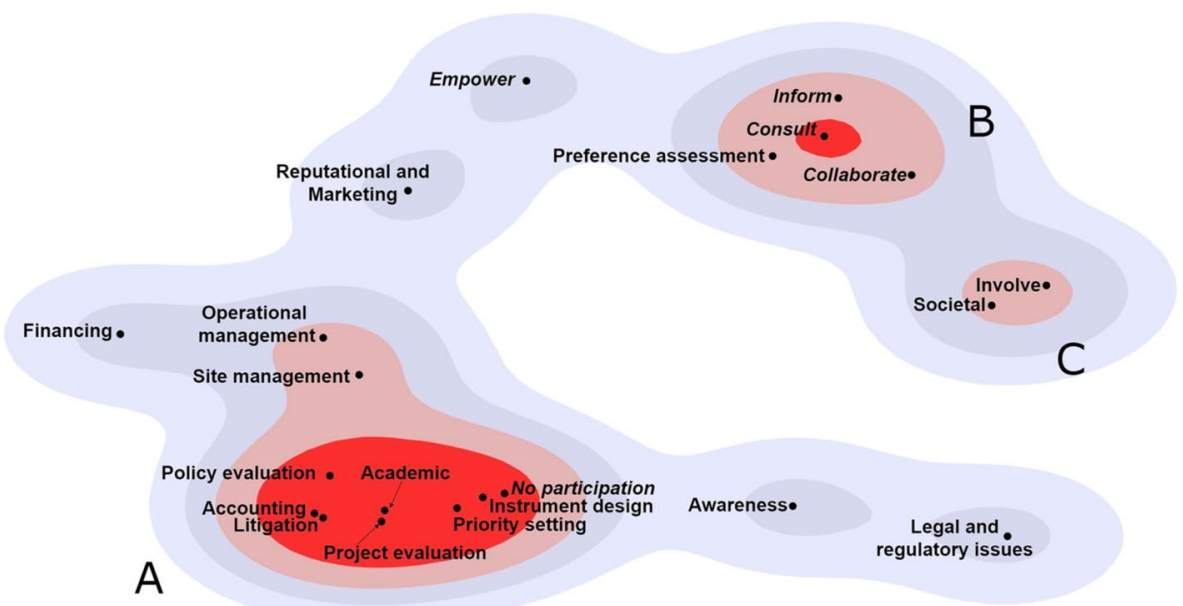


their mapped outcomes $(n=67)$ fall under the broad class of 'Priority Setting' $(24.4 \%, n=33)$. Those use ES maps for prioritizing areas (e.g., ecologically vulnerable areas, recreational areas, areas of conflicts over ES access) by defining hotspots of ES where several ES are provided on a given area. These papers argue using ES maps for priority setting allows framing problems and monitoring changes in ES delivery to define appropriate management strategies and actions (e.g., spatially target areas for environmental restoration), or test the impact of alternative policies. However, $50.4 \%$ of papers made no clear statement on the decision context associated with the produced maps $(n=69)$ other than academic purposes. 'Policy evaluation', 'Instrument design', 'Preference assessment', and 'Societal purposes', dominate the second group of decision contexts (ranging from $11.1 \%$ to $11.9 \%$ ). Policy instruments designed with the ES maps produced in the papers were diverse: e.g., setting up monitoring systems; developing incentive mechanisms, such as compensation payments; or, designing mitigation measures to recover environmental damage. In support of policy evaluation, the papers essentially produced ES maps to assess the performance of instruments and policy measures aimed at improving ES provision. Flexibility is also discussed in the papers through method substitution. Indeed, methods for ES mapping are considered by the papers as substitutable depending on data availability (e.g., using publicly available data in data-scarce regions) and the problem to solve. In sum, ES mapping practices are claimed to be highly customizable to fit specific needs.

Learnability is defined in this paper as the ease with which new users can rapidly achieve optimal performance when using something new to them. We refer to optimal performance as the production of consistent and predictable results with accepted standards. Overall, learnability as a component of usability is not well defined in the papers collected. On the contrary, the papers discuss more the rigorous and complex nature of ES mapping along with difficulty to produce consistent and accurate results. To overcome the low levels of predictability and consistency, studies recommend using ES maps combined with other spatial information (e.g., maps of biodiversity, migration routes, vulnerable species) to guide decision-making efficiently. Moreover, learnability is increased when users are allowed to learn from previous experiences, a parameter that is not discussed by any of the papers. Therefore, although $71.9 \%$ of papers make statements of the usability of their results for decision-making, few are these drawing explicitly on the ease of learning the methodology and replicating it while producing consistent results.

We finally considered robustness as the combination of responsiveness, replicability, and accuracy. Overall, robustness is rarely documented in the context of ES mapping studies, demonstrating a need to understand better the conditions in which ES maps provide robust information for decision-making. First, the use of indicators sensitive to change is required to obtain responsive mapping results. Responsiveness of ES indicators used for mapping is essential for the adoption of ES maps. If maps are out-of-date and are not sensitive to changes, the information provided by the maps could misguide decision-making, especially if map uncertainties are not clearly stated. The papers analyzed highlight the difficulty of developing highly sensitive indicators because it requires a good understanding of the drivers of change. However, they point out the importance of developing indicators sensitive to external impacts to guide decision-makers in the adaptation of management measures in accordance with pressures. We found the methods used in most papers could be difficult to apply to other regions or for other problems to solve, or failed to mention the results' potential to do so. However, a small share of the papers analyzed claimed their methods are replicable in other locations (e.g., replication from an island to another) or consistent with other ES studies on the same territory. Nevertheless, papers generally failed to state clearly the uncertainties of their results. Map uncertainties find their sources in data inputs and methods used for the quantification of ES. For example, Wang et al. (2018) tested the influence of using different quantification methods and found important variations in the accuracy levels of mapping outcomes, which greatly influenced their reliability.

\subsection{Key policy recommendations}

Half the papers made policy recommendations (48.9\%, $n=66$ ), most of them without using participatory approaches $(62.1 \%, n=41)$. The main decision contexts for which these policy recommendations were made covered academic purposes $(18.5 \%, n=25)$ and priority setting $(16.3 \%, n=22)$. In a lesser proportion, decision contexts also covered preference assessment $(8.9 \%, n=12)$, policy evaluation $(7.4 \%$, $n=10)$, and societal analysis $(6.7 \%, n=9)$. From the analysis of the content of the papers, we identified four types of policy recommendations:

\subsubsection{Recommendation 1: harmonize semantics to allow cross-sectoral frameworks for ES mapping}

Papers argue for the development of cross-sectoral multidisciplinary frameworks and indicators, as ES mapping can contribute to a broad range of policy questions, and one ES map can answer several policy objectives. This could lead to cost-saving approaches to policy strategy and design. However, these papers identified the fragmentation of government bodies (e.g., the separation between agriculture and water departments) as hindering the integration of ES concepts in multidisciplinary strategies. A solution would 
be to create semantic links between policy tools of different government bodies and create a link between these tools and ES tools.

\subsubsection{Recommendation 2: use ES maps in support of existing policies relying on mapping outcomes}

Papers highlight windows of opportunity for the use of ES mapping in policies relying heavily on spatially explicit information. We found ES policy implications for European strategies, such as the EU Water Framework Directive (WFD) and the Marine Spatial Planning (MSP), received special attention. Papers proposing this recommendation establish a path between the ecological functions assessed in these strategies with ES supply relying on these functions (e.g., the link between habitat provision and species richness). Papers argue policies could use ES maps with other spatial information to enhance the general benefits of strategic planning, highlighting the need to better balance the use of biophysical metrics (dominant use) with other metrics such as socio-cultural components, often neglected in these policies. For example, Keeler et al. (2019) argue the general lack of inclusion of both biophysical and socioeconomic data in decision-making leads adversely to either decisions made for societies or decisions made for the environment. It is suggested to ponder economic, social, and environmental aspects when including ES maps in planning strategies to combine ecosystem protection with sustainable socioeconomic development.

\subsubsection{Recommendation 3: use ES maps to support sustainable urban planning}

In the context of growing global urbanization, ES assessments for urban landscapes are widely discussed in the papers reviewed. Due to their spatially explicit nature, policies dealing with landscapes should rely on maps to support policy-making and to assess their effects on land-use changes. However, only $7.4 \%$ of the papers analyzed in this study proposed policy recommendations for the purpose of policy evaluation. Land-use change constitutes a major threat to ES supply. The papers dealing with urban planning suggest making use of ES mapping to design policies for two main purposes: First, for green corridors' development, to maintain the flow of ES delivery in urban areas while ensuring equal distribution of urban ES to the populations, and second, for the development of land-sparing' strategies, to avoid chaotic urban development while increasing the resilience of existing natural areas. We found a common obstacle to the implementation of ES maps for urban planning. There is an agreement on the difficulty to define the spatial boundaries of ES, as ES delivery do not end with administrative boundaries. The authors suggest not limiting ES assessments to small areas, but instead broadening the extent of studies. Papers encourage policy-makers to: (1) consider as many ES types as possible and (2) to understand trade-offs and synergies between ES and pressures affecting urban areas by mapping ES not only within urban area boundaries.

\subsubsection{Recommendation 4: build capacity to promote locally relevant policy-making}

While top-down approaches are needed to enforce measures, organize human activities, and preserve natural areas, bottom-up approaches are also key to designing policies more adaptive to local realities. Papers argue the usefulness of bottom-up approaches to fit decisions to populations' needs for ES (e.g., dependency on natural resources). These recommendations link directly to stakeholder participation, which is believed to foster interest and acceptance of decisions while developing a shared knowledge system, a 'mutual learning phase'. Policy regulations should therefore attempt to connect ES supply and demand at the local level to improve populations' access to ES. Two key solutions to build capacity were discussed in the papers: (1) policymaker training and (2) technical guidance proposed by communities of practice.

\subsection{Key research recommendations}

Research recommendations were made by over half the papers analyzed $(66.7 \%, n=90)$, for the most part without using participatory approaches $(67.8 \%, n=61)$. Nearly half $(43.3 \%, n=39)$ of these recommendations are given in a decision context. Priority setting $(16.3 \%, n=22)$ was the main decision context (other than academic purposes) for which these research recommendations were made. In a lesser proportion, decision contexts also covered 'Societal' analysis $(6.7 \%, n=9)$, 'Policy evaluation', 'Instrument design', and 'Preference assessment' (each 5.9\%, $n=8$ ). From the analysis of the papers' content, we identified four types of research recommendations:

\subsubsection{Recommendation 1: ensure transparency on mapping processes and related uncertainties}

ES maps can be perceived as being risky to use in support of decision-making due to the large uncertainties associated with their content. Communication on ES maps uncertainties is a very common recommendation made to researchers by the studies reviewed. The absence of rigorous quantitative methods for assessing uncertainties constrains the usefulness and legitimacy of resulting maps. ES study should highlight biases, generalizations, and uncertainties to determine whether uncertainty levels are too important to be used for sound decision-making or not. Using uncertain results could 
increase the risk of taking harmful decisions for the environment, waste limited public resources, and create conflicts between researchers and practitioners. An obstacle to reducing the gap between theoretical knowledge and its practical use for decision- and policy-making is the disciplinary fragmentation of ES studies. The solutions exposed in the papers encompassed: (1) unifying methods for ES mapping; (2) requiring researchers to make a clear statement on results' quantitative or qualitative uncertainties; and (3) developing standards to achieve interoperability among varying ES tools.

\subsubsection{Recommendation 2: select carefully the appropriate spatial scale for ES mapping}

Most papers collected identified the inconsistency of spatial scales as the primary barrier for understanding and predicting ES trends. This was the case, since a given ES on a territory can be represented at different scales (e.g., quantification of ES per grid cell, per municipality, per watershed), depending on the problem identified. The papers debate on the dominant use of coarse spatial resolutions for ES mapping based on the attribution of an ES quantity per Land Use Land Cover (LULC, e.g., Corine Land Cover). This proxy-based approach follows the assumption that if one LULC class provides an ES, the supply level is considered constant within the class, no matter the internal variability of the ecosystem (e.g., level of degradation). This is considered as leading to generalization errors and unreliable outputs for local decision-making. Moreover, the inconsistency in approaches and scales limits the comparison of ES patterns and scientific findings from different authors. Some authors suggest using models based on proxies, which are time-efficient and low-cost approaches, but propose to refine these units to better account for their spatial variations (e.g., account for geodiversity, soil ES, or parcel data) and to produce more reliable results at a scale understandable and usable for decision-makers.

\subsubsection{Recommendation 3: investigate ES interactions and links with human well-being}

The mapping of ES mostly relies on the visualization of ES supply but less on the mapping of ES demand and capacity due to a persistent theoretical gap in ES research. A clear distinction between these components is needed to understand the flow of ES, how and where they benefit people, and to avoid conflicts over ES access. Another research gap discussed is the poor understanding of the relationship that connects ecosystem conditions with human well-being. As ES concepts are by nature positioned in a transdisciplinary context, studies should draw special attention to linking ecosystem characteristics with socio-cultural components.
Four research needs were put forward in the papers. First developing different sets of explaining variables to map ES supply and demand. Second, mapping ES delivery and ES demand separately and provide recommendations on how to connect ES delivery with beneficiaries. Third, creating an explicit path linking ecosystem conditions with human well-being and communicating this link to raise awareness and improve the uptake of ES maps for decision-making. Fourth, developing metrics for ES quantification sensitive to human actions to demonstrate the importance of this link.

\subsubsection{Recommendation 4: monitor ES trends over time to assess policy performance}

The last type of research recommendation emerging for the content analysis of the papers is the need to plan better for the future, based on temporal analyses. If ES maps are to be valuable for priority setting, policy design, policy, and project evaluation (e.g., understanding the effects of past decisions on the actual state of ecosystems), future research must focus on monitoring ES and predicting their trends. ES maps often produce a static vision of ES, which does not allow for sustainable planning. If policies are expected to be adaptive to change, research outcomes must provide guidance by keeping track of trends in ES delivery, and spot synergies and trade-offs between ES in relation to different scenarios. Linking ES trends with management strategies and policy implementation can lead to pointing out which actions will generate ES gains. Five future research needs on temporal analysis are put forward in the papers. First, baselines should be set for ecosystem's condition against which ES changes could be monitored over time. Second, ecosystem drivers for change and historical landscapes should be better understood to determine how and where land-use changes will affect ecosystems, resulting in a common set of indicators highly sensitive to changes. Third, ecological thresholds and tipping points should be considered in spatial models. Fourth, plausible scenarios should be developed, consistent and relevant to policy questions. Finally, decision and strategies should be confronted with projected ES trends for project and policy evaluation.

\section{Discussion}

\subsection{How to improve stakeholder participation?}

In the survey led by Vorstius and Spray (2015), a diversified group of actors identified three needs for using ES maps: (1) meaningful outputs (i.e., robustness), (2) user friendliness, and (3) stakeholder participation. Interestingly, the scientific narrative on ES mapping in this study refers very little to the first two needs, and our results demonstrate there is still 
progress to be made in stakeholder participation. Indeed, our results are consistent with Lautenbach et al. (2019), who recorded stakeholder participation in 37\% of ES mapping studies from 2000 to 2015, with a share stable over time. From 2015 to 2020 , we found $31.7 \%$ of papers using stakeholder participation with an average of $5.5 \pm 1.8$ published papers per year, against $68.3 \%$ and an average of $11.8 \pm 2.5$ published papers per year without stakeholder participation. Stakeholder participation thus remains stable yet low over time, although early participation is widely recognized as a required step to help bridge the science-practice gap (Beaumont et al. 2017; Pagella and Sinclair 2014).

While relatively rare, studies empowering stakeholders have been shown to deal with broader decision-making contexts. Indeed, when decisions were delegated to stakeholders, whether they were policy-makers or local communities, the applications of ES mapping outcomes were found to be used for broader purposes and especially for business relating purposes such as 'Site management', 'Operational management' (e.g., achieve economic gain with ES management), and 'Reputational and Management' (e.g., increase livelihoods). Since empowerment involves delegating decisions to those affected by the problem, empowerment fosters social learning. This calls for an improvement of scientific findings dissemination and popularization along with the development of guidelines helping researchers design studies including stakeholders. Such guidelines should provide details on the type of stakeholders needed for the assessment, depending on the problem identified and the methods used for capturing their knowledge and preferences. Several projects have assessed the technical gaps in ES mapping to provide guidelines and frameworks that could favor an uptake of ES concepts (e.g., OpenNESS, ESMERALDA), but far less is known about stakeholders' preferences and motivation to adopt ES mapping in their practices. Stakeholder preference analysis is important to develop a broader knowledge of the territory, adapt the research design for greater adaptation to the local context, and as an outcome, increase stakeholder understanding and end-user acceptance. One could argue it is not the scientists' duty to enroll stakeholders in their studies, nor to bridge the science-practice gap. However, the higher the participation, the more problem-driven the research tends to be. Conversely, lower levels of participation were shown to be linked to more knowledgedriven research (Kirchhoff et al. 2013). We found $51.1 \%$ of papers were not rooted in any decision context. In the face of the major threats to the environment, such as pollution, land-use change, or climate change, orienting research outcomes towards real-world problem solving (Nahuelhual et al. 2020) is urgent. Inversely, we believe existing incentives (e.g., payment for ES, compensation payments for environmental impacts, REDD + financial incentives) mostly promote financial strategies, risking jeopardizing the long-term stakeholder acceptance and participation. If practitioners are expected to incorporate the concept on a day-to-day basis, higher administration should impose incorporating ES through legally binding documents (Ferraro et al. 2021).

\subsection{How to make ES mapping more usable?}

A common assumption in the ES field is the relevance of ES to raise awareness, while leading to more informed decision-making (Schröter et al. 2021). Our results highlight an absence of application of ES studies for awareness raising purposes and few papers aiming at making methods more user friendly. The remaining gap in the learnability of ES mapping impedes the effective transfer of scientific knowledge and techniques to end-users. ES maps present low levels of predictability, considering the various methods and accuracy levels of mapping outcomes. ES mapping methodologies are highly flexible and can be fitted to a specific purpose. However, the multiplication of methods combined with a disagreement on definitions can create even more confusion. Moreover, users require important technical skills, and confusion can occur when applying ES mapping methods due to a lack of common standards. Even in their study on ES map operationalization, Jax et al. (2018) say the method they propose may be burdensome for inexperienced non-scientific users. We believe academia first must cooperate to mainstream work into a limited number of visions to pursue the structuring, the standardization and mainstreaming of the field into well-accepted standards. Indeed, standards and unified semantics are still expected to increase the usability of ES mapping. In their paper, Polasky et al. (2015) argue common standards facilitate the adoption of best practices and improve the learning process of new tools. According to them, the uptake of ES by end-users would increase if standards were defined together with policymakers and managers, and with existing standard-setting organizations. In addition to defining standards, technical guidance is needed to speed up the learning process. Online resources easily accessible for users could guide them in using ES maps based on experiences and newfound accepted standards. For example, the EU-funded MAES initiative provides online supports to guide users in the choice of methods by the means of summarized method factsheets, data requirements and providing relevant scientific literature to illustrate methods used in practice.

Low responsiveness of ES indicators and a lack of transparency on methods and uncertainties reduce the relevance of maps. Le Clec'h et al. (2014) emphasize the "power" held by ES map creators since the data used for mapping is analyzed and prioritized for a purpose, which may introduce biases. Since a map remains a simplification of reality (Harley 1989), protocols must be explicit to ensure transparent, legitimate, replicable, and reproducible results. Moreover, 
a mismatch can appear between the observed properties on the map (e.g., areas of high ES value) and the actual areas of ES supply. For example, a well-preserved ecosystem does not necessarily coincide with a high level of ES delivery, and a mapped ES can conflict with empirical evidence. For instance, a degraded coral reef will see its service of water purification increase substantially due to the overgrowth of macroalgae that have a much higher nutrients uptake rate than coral species (den Haan et al. 2016). However, other services will decrease (e.g., recreational activities, coastal protection, provision for food), so considering a broad bundle of ES is essential to avoid misguiding outcomes. If maps are to be more usable in practice, an arbitration between accuracy and complexity is necessary since increasing the scientific soundness of ES maps often decreases the communicability of the results. We believe, consistently with Carmen et al. (2018), that the ES community should develop simple and transferable methods based on practical examples relevant for policy- and decision-making.

\subsection{What next?}

Sixty years after developing the ES concept, there are still major challenges preventing from an effective use of ES concepts outside the academic realm. In our analysis, six in ten papers dealing with policy recommendations for priority setting have not included policy-makers or any other stakeholders in their study. If academic work is to be put into practice for decision- and policy-making, the collaboration between these stakeholder groups is required. The science-practice gap is a challenging issue, and debates on how to bridge this gap are ongoing. The United Nations Research Institute for Social Development held a conference in March 2020 ("From Science to Practice: Research and Knowledge to Achieve the SDGs") in which the idea of developing incentives for scientists was debated to promote collaboration between researchers and policy-makers. The conference proceedings argue these incentives could help policy-makers influence scientific research in terms of "content, approach, location, and time frame" since policymakers need quick operating solutions, while scientists focus on medium to long-term solutions (Carter 2021). This is also true for practitioners who need ready-to-go methodologies. Polasky et al. (2015) emphasize the difficulty for practitioners to know how to use ES mapping due to a lack of agreement in the research community. We believe scientists should favor existing integrated tools for ES assessment and mapping (see Jax et al. 2018). This links to the need for a common language (Carmen et al. 2018; Polasky et al. 2015) to help mainstream the concepts through standardized methods and homogeneous output quality. It would improve map comparisons and result dissemination. Handbooks (e.g., Burkhard and Maes 2017) provide key information to users when handling ES concepts. They provide practical guidance, illustrate concepts with case studies, and set 'best practice' standards (Lautenbach et al. 2019). Governing instances could also provide such guidelines to decisionmakers willing to map ES. Well-established practices, such as Environmental Impact Assessments, could serve as a model for integrating ES assessment and mapping on the international scene. For example, the United Nations Statistical Commission adopted in March 2021 the SEEA Ecosystem Accounting framework. This framework was tested by Farrell et al. (2021), who found it to be both feasible and effective for the management of water resources. It provides a clear path between ecosystem characteristics (ecosystem extent and conditions), monetary ecosystem assets, and human well-being. Such a work is also necessary for nonmonetary approaches and these links should be made clear to practitioners in order to foster their acceptance.

To improve the reliability and legitimacy of ES maps, future research is needed on risk communication, spatial scale aggregation, and temporal analysis. Papers should communicate better on risks related to the result uncertainties to foster trust in academic findings. Lautenbach et al. (2019) argue it should be mandatory to expose quantified uncertainties to help decision-makers decide whether results are reliable enough to support their decisions. The lack of transparency of the research process and communication of biases inhibits stakeholder learning and prevents stakeholder acceptance of ES use. Uncertainties are, however, not unique to ES studies. For example, climate change skeptics criticize climate actions (Huber 2020) and exploit climate science uncertainties. Uncertainty could be reduced by developing standardized frameworks for ES assessment and mapping, as discussed previously. Standards are required to bring together the various disciplines and provide straightforward recommendations for their practical use.

A recent literature review (Nahuelhual et al. 2020) also highlights the need to find methods that could integrate data from different spatial scales. Modeling approaches relying on empirical data provide more reliable information but are often restricted to local-scale assessments and consider few ES. Schröter et al. (2021) negate the assumption of a linear relationship between land cover and ES supply, which does not account for internal variation. While broad assessments (region, nation) have increasingly consistent methodologies relying on standards for LULC classification, this is still not the case for local applications. We believe it is important to propose indicators for ES quantification and mapping per ES, with standards for large-scale assessments, mediumscale assessments, and small-scale assessments, along with methodologies to upscale local assessment into larger areas or regions. An overlapping of studies on different spatial scales would allow the validation of large-scale assessments, while providing reliable information for local management. 
The papers analyzed commonly brought up the need for temporal analysis in ES trends. Nahuelhual et al. (2020) argue the static vision on ES limits the usefulness of ES maps, especially since ecosystem responses to management can occur over long periods. According to the SEEA report, ES maps do not support well long-term trend analysis. They recommend combining spatially explicit ES approaches for hotspot delineation with non-spatially explicit ES approaches to provide broad overviews of key ES trends.

The global findings of our review led us to develop a conceptual framework (Fig. 4) elucidating one of the possible pathways to bridge the science-practice gap in ES mapping. The framework comprises six building blocks we identified as key to reconciling scientific knowledge on ES and their inclusion into policy- and decision-making. These steps are as follow: (1) Increase the scientific soundness of methodologies to map ES and base maps on the best scientific evidence available; (2) Pursue efforts in the clarification of the link between ecosystem conditions and human well-being in order to increase stakeholder understanding; (3) Develop generic user-friendly tools and indicators for ES assessments to increase the usability of ES mapping methodologies for non-academics. Once methods are made more robust, the link between ecosystems and human well-being is clear, and tools are made more easily accessible, it will be possible to (4) have stakeholders participating in the assessment of ES and the design of maps and to guide future users and build experience knowledge it is necessary to (5) develop best practices based on a common language. At last, (6) ES tools should be tailored to policy needs to increase the usability of ES maps for decision- and policy-making.

This study has a number of limitations. As our aim was to analyze scientific narratives on the four research questions in a systematic way, grey literature was left out of the study. These could have provided additional information regarding concept mainstreaming and the effective use of ES mapping for decision-making. In addition, our systematic review was performed using keywords directly relating to ES mapping. Related terms could have been used in the search, such as 'monitoring', 'indicators', 'spatial', or 'nature contribution'. However, we are confident the large body of papers analyzed for this study provides a reliable understanding of the narratives regarding the usability of ES mapping for decision-making and identifies ways to increase their practical use. This paper is also one of the first attempts to introduce Ergonomics in the narrative analysis of ES map usability for decision-making. However, the Ergonomics principles could have been tested with a range of other criteria, determining in quantitative terms the usability levels of papers. To do so, further studies could focus only on ES mapping case studies. For example, Joly et al. (2021) tested in a case study the application of principles from Cognitive Ergonomics to identify the most beneficial agricultural management practice for both farmers and ES bundle optimization. Nevertheless, our methodology was useful to pinpoint the current state of the art on ES mapping potential for decision-making and the recommendations made to scientists and to policy-makers on how to move forward to bridge the science-practice gap.

\section{Conclusion}

In this paper, we carried out a systematic review of ES map usability for decision-making by analyzing 135 peerreviewed papers. Papers were analyzed in consideration of four criteria: the participation of stakeholders, the usability of ES maps, policy recommendations, and research recommendations.

Our results revealed that ES maps are not yet readily usable for decision-making and confirmed the gap between
Fig. 4 Building blocks that could help bridge the gap between scientific knowledge production and users in support of decision and policy-making based on Ecosystem Service (ES) mapping and assessment

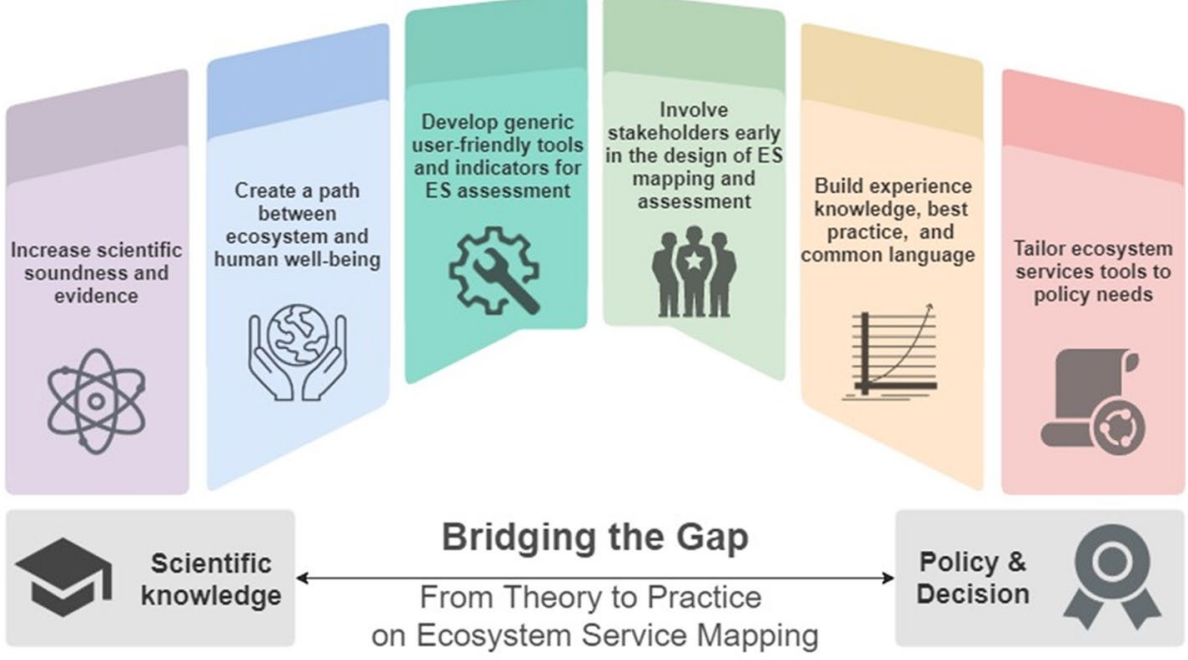


ES mapping research and their use in practice. Indeed, our results suggest new users may experience difficulties to become proficient when mapping ES or when using mapped outcomes. This, in addition to high levels of uncertainties associated with ES maps, may discourage the use of ES mapping for decision-making. As a result, little of the abundant ES research directly supports decisions (Olander et al. 2017). We identified two major constraints to the operationalization of ES mapping: (1) the lack of a common language in the field and the diversity of mapping methods; and (2) the insufficient participation of stakeholders in ES study design. To increase map usability, paths for improvement are threefold: (1) improving the ease with which new users can map ES and use existing maps to achieve high performance in decision-making; (2) developing generic indicators customizable to local conditions; and (3) increasing the reproducibility of mapping methods.

As advocated in the FAIR Data Principles, scientific data should be Findable, Accessible, Interoperable, and Reusable (Wilkinson et al. 2016). Along with this ideology, we posit ES mapping methods and tools should follow similar principles to improve their implementation. This could promote the operational, consistent, and replicable use of tools and methods. Developing a collaborative open-data Web platform to collect ES maps could be one of the ways to move forward. Researchers should be encouraged to share their findings and reference them, promoting their interoperability consistently with the FAIR data standards. With harmonized ES semantics and interoperable datasets, scientific findings could be more easily shared, improving institutional learning (Finisdore et al. 2020). Such a platform would not only increase the visibility of ES mapping outputs to decisionand policy-makers but also allow researchers to identify blank areas where ES assessments are needed and reveal inconsistencies with other maps to encourage scientific collaboration.

Our findings show promising outcomes for ES mapping in policy-making. ES maps provide a useful framework to link ecological processes to human well-being, but access to comparable data and evidence of this link should be made clear. ES maps can help bridge sectoral fragmentation between government bodies while encouraging the implementation of multidisciplinary approaches. This is especially true since many policies rely on mapped outcomes, creating a window of opportunity for the policy uptake of ES mapping. Moreover, ES maps are found to be highly useful for urban planning. Indeed, well-designed maps can help evaluate the effects of current and future land-use changes on ecosystems and human welfare. However, ES concepts need further popularization to foster public awareness and promote capacity building.
Supplementary Information The online version contains supplementary material available at https://doi.org/10.1007/s10669-021-09839-7.

Acknowledgements We would like to thank the constructive comments of three anonymous reviewers who helped improve the quality and relevance of the manuscript.

Author contributions All authors contributed to the study's conception and design. REB performed the material preparation, data collection, and analysis. REB wrote the draft manuscript and all authors commented on previous versions of the manuscript. All authors read and approved the final manuscript.

Funding The paper was supported by the European Union under grant agreement $n^{\circ} 07.027735 / 2019 / 808239 / S U B / E N V . D 2$, MOVE-ON Project (From case studies to anchor projects-setting the ground to advance MAES in Europe's overseas).

Data availability The query used to collect papers is detailed in Supplementary Materials A. All papers collected for this analysis are referenced in Supplementary Material B. Additional data used for the analysis of this study are available in Supplementary Material C and D.

\section{Declarations}

Conflict of interest The authors declare that they have no conflict interests.

Disclaimer This project has been funded with support from the European Union represented by the European Commission DirectorateGeneral Environment. This publication reflects the views only of the authors, and the Commission cannot be held responsible for any use which may be made of the information contained therein.

Open Access This article is licensed under a Creative Commons Attribution 4.0 International License, which permits use, sharing, adaptation, distribution and reproduction in any medium or format, as long as you give appropriate credit to the original author(s) and the source, provide a link to the Creative Commons licence, and indicate if changes were made. The images or other third party material in this article are included in the article's Creative Commons licence, unless indicated otherwise in a credit line to the material. If material is not included in the article's Creative Commons licence and your intended use is not permitted by statutory regulation or exceeds the permitted use, you will need to obtain permission directly from the copyright holder. To view a copy of this licence, visit http://creativecommons.org/licenses/by/4.0/.

\section{References}

Arnstein SR (1969) A ladder of citizen participation. J Am Inst Plan 35(4):216-224. https://doi.org/10.1080/01944366908977225

Beaumont NJ, Mongruel R, Hooper T (2017) Practical application of the ecosystem service approach (ESA): lessons learned and recommendations for the future. Int J Biodivers Sci, Ecosyst Serv Manag 13(3):68-78. https://doi.org/10.1080/21513732.2018. 1425222

Brunet L, Tuomisaari J, Lavorel S, Crouzat E, Bierry A, Peltola T, Arpin I (2018) Actionable knowledge for land use planning: Making ecosystem services operational. Land Use Policy 72:27-34. https://doi.org/10.1016/j.landusepol.2017.12.036 
Burkhard B, Maes J (Eds.) (2017) Mapping Ecosystem Services. Pensoft Publishers, Sofia, pp. 374. ISBN 978-954-642-830-1

Carmen E, Watt A, Carvalho L, Dick J, Fazey I, Garcia-Blanco G, Grizzetti B, Hauck J, Izakovicova Z, Kopperoinen L, Liquete C, Odee D, Steingröver E, Young J (2018) Knowledge needs for the operationalisation of the concept of ecosystem services. Ecosyst Serv 29:441-451. https://doi.org/10.1016/j.ecoser.2017.10.012

Carter, M. (2021). From science to practice: research and knowledge to achieve the SDGs (policy brief no. 38; Research-Eelated Activities 2020+). United Nations Research Institute for Social Development.

Chen C, Wang Y, Jia J, Mao L, Meurk CD (2019) Ecosystem services mapping in practice: a Pasteur's quadrant perspective. Ecosyst Serv 40:101042. https://doi.org/10.1016/j.ecoser.2019.101042

Cowling RM, Egoh B, Knight AT, O'Farrell PJ, Reyers B, Rouget M, Roux DJ, Welz A, Wilhelm-Rechman A (2008) An operational model for mainstreaming ecosystem services for implementation. Proc Natl Acad Sci 105(28):9483. https://doi.org/10.1073/pnas. 0706559105

Daily GC, Matson PA (2008) Ecosystem services: from theory to implementation. Proc Natl Acad Sci 105(28):9455. https://doi. org/10.1073/pnas.0804960105

de Araujo Barbosa CC, Atkinson PM, Dearing JA (2015) Remote sensing of ecosystem services: a systematic review. Ecol Indic 52:430-443. https://doi.org/10.1016/j.ecolind.2015.01.007

den Haan J, Huisman J, Brocke HJ, Goehlich H, Latijnhouwers KRW, van Heeringen S, Honcoop SAS, Bleyenberg TE, Schouten S, Cerli C, Hoitinga L, Vermeij MJA, Visser PM (2016) Nitrogen and phosphorus uptake rates of different species from a coral reef community after a nutrient pulse. Sci Rep 6(1):28821. https://doi. org $/ 10.1038 /$ srep 28821

Dicks LV, Walsh JC, Sutherland WJ (2014) Organising evidence for environmental management decisions: a ' $4 S$ ' hierarchy. Trends Ecol Evol 29(11):607-613. https://doi.org/10.1016/j.tree.2014. 09.004

Dix A, Dix AJ, Finlay J, Abowd GD, Beale R (2003) Human-computer interaction. Pearson Education, New York

Drakou EG, Crossman ND, Willemen L, Burkhard B, Palomo I, Maes J, Peedell S (2015) A visualization and data-sharing tool for ecosystem service maps: lessons learnt challenges and the way forward. Ecosyst Serv 13:134-140. https://doi.org/10.1016/j.ecoser. 2014.12.002

Drius M, Jones L, Marzialetti F, de Francesco MC, Stanisci A, Carranza ML (2019) Not just a sandy beach. The multi-service value of Mediterranean coastal dunes. Sci Total Environ 668:11391155. https://doi.org/10.1016/j.scitotenv.2019.02.364

Dvarskas A (2018) Mapping ecosystem services supply chains for coastal Long Island communities: implications for resilience planning. Ecosyst Serv 30(A):14-26. https://doi.org/10.1016/j. ecoser.2018.01.008

Egoh B, Reyers B, Rouget M, Richardson DM, Le Maitre DC, van Jaarsveld AS (2008) Mapping ecosystem services for planning and management. Agric Ecosyst Environ 127(1-2):135-140. https://doi.org/10.1016/j.agee.2008.03.013

Farrell CA, Coleman L, Kelly-Quinn M, Obst CG, Eigenraam M, Norton D, O'Donoghue C, Kinsella S, Delargy O, Stout JC (2021) Applying the system of environmental economic accountingecosystem accounting (SEEA-EA) framework at catchment scale to develop ecosystem extent and condition accounts. One Ecosyst 6:e65582. https://doi.org/10.3897/oneeco.6.e65582

Ferraro, G., Trégarot, E., \& Failler, P. (2021). Constraints and solutions for the implementation of MAES in European overseas (p. 29) [Deliverable 5.2]. MOVE.

Finisdore J, Rhodes C, Haines-Young R, Maynard S, Wielgus J, Dvarskas A, Houdet J, Quétier F, Lamothe KA, Ding H, Soulard F, Van Houtven G, Rowcroft P (2020) The 18 benefits of using ecosystem services classification systems. Ecosyst Serv 45:101160. https:// doi.org/10.1016/j.ecoser.2020.101160

Harley J (1989) Deconstructing the map. Cartographica 26:1-20

Hauck J, Goerg C, Varjopuro R, Ratamaki O, Maes J, Wittmer H, Jax K (2013) "Maps have an air of authority": potential benefits and challenges of ecosystem service maps at different levels of decision making. Ecosyst Serv 4:25-32. https://doi.org/10.1016/j. ecoser.2012.11.003

Huber RA (2020) The role of populist attitudes in explaining climate change skepticism and support for environmental protection. Env Polit 29(6):959-982. https://doi.org/10.1080/09644016.2019. 1708186

Jacobs S, Spanhove T, De Smet L, Van Daele T, Van Reeth W, Van Gossum P, Stevens M, Schneiders A, Panis J, Demolder H, Michels H, Thoonen M, Simoens I, Peymen J (2016) The ecosystem service assessment challenge: reflections from FlandersREA. Ecol Indic 61(2):715-727. https://doi.org/10.1016/j.ecoli nd.2015.10.023

Jannach, D., \& Adomavicius, G. (2016). Recommendations with a purpose. In: Proceedings of the 10th ACM conference on recommender systems, 7-10. https://doi.org/10.1145/2959100.2959186

Jax K, Furman E, Saarikoski H, Barton DN, Delbaere B, Dick J, Duke G, Görg C, Gómez-Baggethun E, Harrison PA, Maes J, Pérez-Soba M, Saarela S-R, Turkelboom F, van Dijk J, Watt AD (2018) Handling a messy world: lessons learned when trying to make the ecosystem services concept operational. SI: Synth OpenNESS 29:415-427. https://doi.org/10.1016/j.ecoser.2017. 08.001

Johnson JA, Jones SK, Wood SL, Chaplin-Kramer R, Hawthorne PL, Mulligan M, Pennington D, DeClerck FA (2019) Mapping ecosystem services to human well-being: a toolkit to support integrated landscape management for the SDGs. Ecol Appl 29(8):e01985. https://doi.org/10.1002/eap.1985

Joly F, Benoit M, Martin R, Dumont B (2021) Biological operability, a new concept based on ergonomics to assess the pertinence of ecosystem services optimization practices. Ecosyst Serv 50:101320. https://doi.org/10.1016/j.ecoser.2021.101320

Keeler BL, Dalzell BJ, Gourevitch JD, Hawthorne PL, Johnson KA, Noe RR (2019) Putting people on the map improves the prioritization of ecosystem services. Front Ecol Environ 17(3):151156. https://doi.org/10.1002/fee.2004

Kerr RA (2011) Time to adapt to a warming world, but where's the science? Science 334(6059):1052-1053. https://doi.org/10. $1126 /$ science.334.6059.1052

Kirchhoff CJ, Carmen Lemos M, Dessai S (2013) Actionable knowledge for environmental decision making: broadening the usability of climate science. Annu Rev Env Resour 38(1):393-414. https://doi.org/10.1146/annurev-environ-022112-112828

Lautenbach S, Mupepele A-C, Dormann CF, Lee H, Schmidt S, Scholte SSK, Seppelt R, van Teeffelen AJA, Verhagen W, Volk M (2019) Blind spots in ecosystem services research and implementation. Region Environ Change. https://doi.org/10.1007/ s10113-018-1457-9

Le Clec'h, S., Dufour, S., Oszwald, J., Grimaldi, M., \& Jégou, N. (2014). Spatialiser des services écosystémiques, un enjeu méthodologique et plus encore. In Political ecology des services écosystémiques. (Arnauld de Sartre A. (ed.), Castro M., pp. 205-223).

Longato D, Cortinovis C, Albert C, Geneletti D (2021) Practical applications of ecosystem services in spatial planning: lessons learned from a systematic literature review. Environ Sci Policy 119:72-84. https://doi.org/10.1016/j.envsci.2021.02.001

Lorilla RS, Poirazidis K, Detsis V, Kalogirou S, Chalkias C (2020) Socio-ecological determinants of multiple ecosystem services on the Mediterranean landscapes of the Ionian Islands (Greece). Ecol Model. https://doi.org/10.1016/j.ecolmodel.2020.108994 
Martinez-Harms MJ, Bryan BA, Balvanera P, Law EA, Rhodes JR, Possingham HP, Wilson KA (2015) Making decisions for managing ecosystem services. Biol Conserv 184:229-238. https:// doi.org/10.1016/j.biocon.2015.01.024

Mengist W, Soromessa T, Feyisa GL (2020) A global view of regulatory ecosystem services: existed knowledge, trends, and research gaps. Ecol Process 9(1):40. https://doi.org/10.1186/ s13717-020-00241-w

Moher D, Liberati A, Tetzlaff J, Altman DG, Prisma Group (2009) Preferred reporting items for systematic reviews and meta-analyses: the PRISMA Statement. PLoS Med 6(7):e1000097. https://doi. org/10.1371/journal.pmed.1000097

Nahuelhual L, Benra Ochoa F, Rojas F, Ignacio Diaz G, Carmona A (2016) Mapping social values of ecosystem services: what is behind the map? Ecol Soc. https://doi.org/10.5751/ ES-08676-210324

Nahuelhual L, Vergara X, Bozzeda F, Campos G, Subida MD, Outeiro L, Villasante S, Fernandez M (2020) Exploring gaps in mapping marine ecosystem services: a benchmark analysis. Ocean Coast Manage. https://doi.org/10.1016/j.ocecoaman. 2020.105193

OCDE (2015) Climate change risks and adaptation. OECD, Paris. https://doi.org/10.1787/9789264234611-en

Olander L, Polasky S, Kagan JS, Johnston RJ, Wainger L, Saah D, Maguire L, Boyd J, Yoskowitz D (2017) So you want your research to be relevant? Building the bridge between ecosystem services research and practice. Ecosyst Serv 26:170-182. https:// doi.org/10.1016/j.ecoser.2017.06.003

Pagella TF, Sinclair FL (2014) Development and use of a typology of mapping tools to assess their fitness for supporting management of ecosystem service provision. Landsc Ecol 29(3):383-399. https:// doi.org/10.1007/s10980-013-9983-9

Polasky S, Tallis H, Reyers B (2015) Setting the bar: standards for ecosystem services. Proc Natl Acad Sci 112(24):7356-7361. https:// doi.org/10.1073/pnas.1406490112

Ranganathan, J., Raudsepp-Hearne, C., Nicolas, L., Irwin, F., Zurek, M., Bennett, E., Ash, N., \& West, P. (2008). Ecosystem servicesa guide for decision makers (p. 96). World Resources Institute. pdf.wri.org/ecosystem_services_guide_for_decisionmakers.pdf

Santos-Martin F, Viinikka A, Mononen L, Brander LM, Vihervaara P, Liekens I, Potschin-Young M (2018) Creating an operational database for ecosystems services mapping and assessment methods. One Ecosyst 3:e26719. https://doi.org/10.3897/oneeco.3.e26719
Schröter M, Crouzat E, Hoelting L, Massenberg J, Rode J, Hanisch M, Kabisch N, Palliwoda J, Priess JA, Seppelt R, Beckmann M (2021) Assumptions in ecosystem service assessments: increasing transparency for conservation. Ambio 50(2, SI):289-300. https:// doi.org/10.1007/s13280-020-01379-9

Steel B, List P, Lach D, Shindler B (2004) The role of scientists in the environmental policy process: a case study from the American west. Environ Sci Policy 7:1-13. https://doi.org/10.1016/j.envsci. 2003.10.004

Toomey AH (2016) What happens at the gap between knowledge and practice? Spaces of encounter and misencounter between environmental scientists and local people. Ecol Soc. https://doi.org/ 10.5751/ES-08409-210228

Vorstius AC, Spray CJ (2015) A comparison of ecosystem services mapping tools for their potential to support planning and decisionmaking on a local scale. Ecosyst Serv 15:75-83. https://doi.org/ 10.1016/j.ecoser.2015.07.007

Wang Z, Lechner AM, Baumgartl T (2018) Ecosystem services mapping uncertainty assessment: a case study in the Fitzroy Basin mining region. Water. https://doi.org/10.3390/w10010088

Wilkinson MD, DumontierAalbersberg MIJJ, Appleton G, Axton M, Baak A, Blomberg N, Boiten J-W, Silva Santos LB, Bourne PE, Bouwman J, Brookes AJ, Clark T, Crosas M, Dillo I, Dumon O, Edmunds S, Evelo CT, Finkers R, Gonzalez-Beltran A, Gray AJG, Groth P, Goble C, Grethe JS, Heringa J, 't Hoen PAC, Hooft R, Kuhn T, Kok R, Kok J, Lusher SJ, Martone ME, Mons A, Packer AL, Persson B, Rocca-Serra P, Roos M, Schaik R, Sansone S-A, Schultes E, Sengstag T, Slater T, Strawn G, Swertz MA, Thompson M, Lei J, Mulligen E, Velterop J, Waagmeester A, Wittenburg P, Wolstencroft K, Zhao J, Mons B (2016) The FAIR guiding principles for scientific data management and stewardship. Sci Data 3(1):160018. https://doi.org/10.1038/sdata.2016.18

Wolfswinkel JF, Furtmueller E, Wilderom CPM (2013) Using grounded theory as a method for rigorously reviewing literature. Eur J Inf Syst 22(1):45-55. https://doi.org/10.1057/ejis.2011.51

Zulian G, Stange E, Woods H, Carvalho L, Dick J, Andrews C, Baro F, Vizcaino P, Barton DN, Nowel M, Rusch GM, Autunes P, Fernandes J, Ferraz D, dos Santos RF, Aszalos R, Arany I, Czucz B, Priess J, Hoyer C, Bürger-Patricio G, Lapola D, Mederly P, Halabuk A, Bezak P, Kopperoinen L, Viinikka A (2018) Practical application of spatial ecosystem service models to aid decision support. Ecosyst Serv 29:465-480. https://doi.org/10.1016/j. ecoser.2017.11.005 